\title{
The Effect of Partner Sex: Nondisclosure of HIV Status to Male and Female Partners Among Men who Have Sex with Men and Women (MSMW)
}

\author{
Tara McKay $\cdot$ Matt G. Mutchler
}

Published online: 17 November 2010

(C) The Author(s) 2010. This article is published with open access at Springerlink.com

\begin{abstract}
A common concern within HIV prevention is that HIV positive MSMW do not disclose their HIV status to female partners who are thus at increased risk for HIV infection. The present study uses unique data to examine whether MSMW disclose more often to male rather than female partners. Data were collected on most recent male and/or female primary partner and four most recent casual partners from 150 MSMW (50 African American, 50 Latino, 50 White). MSMW reported on 590 partners (31\% female; $69 \%$ male). Disclosure was coded as disclosure before sex, disclosure after sex, or nondisclosure. A series of multinomial logistic regressions with partners clustered within respondents were conducted to evaluate effects of respondent characteristics and partner characteristics on timing of disclosure. In bivariate and multivariate analyses there were no significant differences in odds of disclosure to male and female partners before or after sex. Although MSMW were substantially less likely to disclose to HIV negative partners before sex compared to HIV positive partners regardless of sex, when we fully interacted the multivariate model by partner sex, the odds of disclosure to HIV negative male partners compared to HIV positive
\end{abstract}

T. McKay (ه)

Department of Sociology, University of California,

Los Angeles, 264 Haines Hall, 375 Portola Plaza,

Los Angeles, CA 90095, USA

e-mail: tmckay@ucla.edu

M. G. Mutchler

Department of Sociology, California State University, Dominguez Hills, Carson, CA, USA

T. McKay · M. G. Mutchler

Community Based Research, AIDS Project Los Angeles,

Los Angeles, CA, USA male partners before sex were significantly higher than the odds of disclosure to HIV negative female partners compared to HIV positive female partners. Patterns of mutual nondisclosure and nonreciprocal disclosure were observed with both primary and casual partners. The paper makes additional methodological contributions to the measurement and analysis of disclosure.

Keywords Disclosure $\cdot \mathrm{HIV} \cdot$ Bisexual $\cdot$ Men who have sex with men and women (MSMW) - Risk · Responsibility $\cdot$ Female partners $\cdot$ Measurement

Communication about stigmatized identities and behaviors takes place within complex interpersonal and social contexts. For HIV positive men who have sex with men and women (MSMW) disclosure of sexual behavior and HIV positive status present unique problems with male and female sexual partners. A common concern within HIV prevention is that MSMW may not disclose to female partners who, unaware of their partner's sexual behavior and HIV status, are at increased risk for infection. These concerns have been raised particularly for Black and Latino men who have sex with men (MSM) since they have been observed to be more likely than White MSM to have female partners [1-3] but are less likely to disclose their bisexual behavior to female partners [3, 4]. Yet, rates of disclosure of HIV status to both male and female partners by HIV positive MSMW generally and across race/ethnicity and sexual orientation remain unknown. The following study aims to describe patterns and identify determinants of disclosure to male and female sexual partners among HIV positive MSMW using a unique data set that provides information on respondent and partner characteristics. 
A number of studies have observed that individual assessments of the benefits and risks of disclosure are important determinants of whether individuals disclose their HIV status to anyone, including sexual partners. The widely used Disclosure Decision Model [5] argues that decisions to self-disclose personal information are a function of the strategic evaluation of the individual and social risks and benefits of disclosure. Work formally and informally within this risk/benefit framework has sought to identify characteristics of HIV positive individuals and their partners or relationships that influence disclosure of HIV status by increasing or decreasing the personal and social risks to the discloser.

In popular discussions of disclosure of HIV status among MSMW, disclosure to female partners is often assumed to be less frequent than disclosure to male partners, as disclosure to female partners entails substantially greater risk than disclosure to male partners who are, at the very least, already aware of their partner's same-sex sexual behavior. However, with the exception of recent work using the present data set [6], the authors are not aware of additional studies that disaggregate disclosure of HIV status by partner gender among MSMW or among men who have sex with men (MSM) more broadly. Although there is some evidence that female relatives are more likely to be disclosed to by MSM [7], it is not clear whether this trend extends to intimate relationships. In a qualitative study of disclosure to various targets, including family members, friends, and sexual/relationship partners, Cusick and Rhodes [8] present nondisclosure as a means of protecting not only the personal relationship between HIV positive individual and another, but also as protecting "fixed social relationships" such as "husband", "boyfriend", or "father". Within this framework, we might think of disclosure to female primary partners as being accompanied by greater potential to disrupt MSMW's social roles as husbands or fathers. Thus MSMW may avoid disclosure of their HIV status to female partners more so than to male partners. Further, MSMW may avoid disclosure to female partners on the grounds that female partners are perceived to be more likely to respond negatively to information that their partner is HIV positive and may be more likely to question his fidelity or sexual orientation if he discloses that he is HIV positive [9].

Despite the risks involved in disclosure, a growing body of work finds that HIV positive individuals see themselves as having a duty or responsibility to disclose to others, particularly those who might be at risk of infection. HIV positive individuals frequently disclose to primary partners $[10,11]$ and often acknowledge an obligation to disclose to partners [8, 12]. Qualitative investigation of this phenomenon by Cusick and Rhodes [8] and others finds that, in addition to a risk/benefit analysis, HIV positive individuals frame disclosure as a personal responsibility to partners and for partners' health. Some conceptualize this responsibility more broadly, citing a social responsibility to public health aims of decreasing HIV transmission [13]. Beliefs about responsibility to disclose may be further supported by fears of legal action among some men [14]. Thus, despite unbalanced risks, HIV positive MSMW may be similarly motivated to disclose to both male and female primary partners to whom they feel personally responsible while remaining generally unmotivated to disclose to either male or female casual partners.

In order to evaluate differences in disclosure of HIV status to male and female partners by MSMW, we must also consider the role of other factors that contribute to variation in disclosure behaviors, including: sexual orientation, race/ethnicity, relationship status, partner's HIV status. Overall rates of disclosure vary widely across studies and measures of disclosure [15], with estimates of nondisclosure ranging from 2 to $52 \%$ in studies conducted between 1991 and 2001 among MSM [16]. However, in line with arguments that greater benefit and less risk may be derived from primary partners who are more emotionally and materially invested in the discloser, a number of studies show that HIV positive individuals are more likely to disclose to primary partners than to casual partners [17-20]. Similarly, HIV positive MSM are more likely to disclose to HIV positive partners than HIV negative or unknown partners to avoid rejection from potential partners $[14,21]$.

Rates of disclosure have been observed to vary by sexual orientation, with gay and bisexual men (pooled; $42 \%$ ) being more likely than heterosexual men (19\%) and heterosexual women (17\%) to engage in any sex without disclosure, primarily in nonexclusive partnerships [22]. However, in the same study, gay and bisexual men reported similar rates of any sex without disclosure in exclusive or primary partnerships (6\%) compared to heterosexual men $(10 \%)$ and heterosexual women (8\%), identifying relationship status as an important third variable. Few studies consider gay and bisexual men distinct populations, which makes comparisons of rates of disclosure by self-identified sexual orientation and/or sexual behavior difficult. Among MSMW, however, recent work finds that the predictive value of sexual orientation, assessed using the Klein sexual orientation grid [23], interacts with race/ethnicity and partner gender [6].

Studies of disclosure behavior by race/ethnicity present mixed findings. Disclosure of sexual behavior and HIV status are thought to be inhibited by contexts that increase the real or perceived personal and social risks of disclosure. Homophobia and HIV stigma in communities of color may increase the risk of disclosure of HIV status among Black and Latino MSM and MSMW. Black and Latino MSMW 
may not openly identify as gay or bisexual due to stigma associated with homosexuality and HIV in communities of color [24-27]. There is some evidence in support of these explanations for lower rates of disclosure of HIV positive status among Black and Latino MSM. In a convenience sample of care-seeking HIV positive individuals, those identifying as White or Latino had 3 times the odds of disclosing their HIV status to all sexual partners in a 6-month period compared to those indentifying as Black [19]. Yet other work finds negligible differences in rates of HIV disclosure to primary partners among care-seeking Black and White MSM who report disclosing to 89 and $97 \%$ of current primary sexual partners, respectively [28]. Among Latino men, broader cultural norms regulating disclosure of personal information and the protection of others from worries or stigma may also limit disclosure [25].

In sum, the present study aims to describe patterns of disclosure to male and female partners while controlling for additional known determinants of disclosure to sexual partners. We utilize a unique data set that includes detailed sexual histories of the male and female sexual partners of HIV positive men who have sex with men and women (MSMW). The study also applies methodological innovations in the study of disclosure of HIV status by disaggregating disclosure before sex and disclosure after sex [29] and by including multiple observations of an individual MSMW's disclosure behaviors.

Multiple observations are necessary because disclosure is not an absolute event; we know well that different factors influence disclosure across different targets [12, 25, 30]. Although the inclusion of multiple targets (e.g., sexual partners, family, and close friends) in analyses of disclosure is common, the inclusion of multiple observations of the same type of target, such as sexual partners, is rare. Often, disclosure is assessed at the most recent or current sexual partnership [31]. Yet, among MSM there is wide variability in patterns of disclosure to partners: in their study, Parsons and colleagues observe that some MSM disclose to all casual partners (29\%) while others disclose to none $(33 \%)$, and still others disclose selectively to only some casual partners (38\%) [32]. Similarly, in findings from a longitudinal study of disclosure by STD clinic attendees who were surveyed about their disclosure behaviors at baseline and to any new partners at follow-up, $30 \%$ of participants reported inconsistent disclosure behaviors (disclosing to one partner but not the other). Given this variability, the present study utilizes sexual history data for up to one male and one female primary partner and up to four casual partners in the 5 years prior to interview to provide more exact estimates of disclosure among MSMW. Further, this data structure is used to maximize observations for female partners.

\section{Methods}

Data were collected from participants recruited via posters and flyers at the eight social service and health-related AIDS organizations funded by Los Angeles County to target MSMW for primary or secondary HIV prevention activities from August, 2002 through July, 2004. The final sample consisted of 150 HIV positive MSMW. A targeted sampling strategy was used to obtain equal numbers of MSMW participants by race/ethnicity: 50 Black, 50 Latino, and 50 White. Within the Latino sample, we recruited 25 Spanish monolingual Latino men to reflect the linguistic composition of this racial/ethnic group in Los Angeles County.

MSMW was defined as a male who self-reported sex with at least one male and at least one female partner in the previous 5 years. This definition is consistent with definitions used in prior work [27, 33]. Using a longer time period allows for analyses of sexual patterns and relationships over time. Men who engage in bisexual behavior may not identify as bisexual and may not engage in polyamorous relationships; thus their sexual practices with men and women may only be captured over a time period that is measured over several years [34].

Potential participants were screened via phone. Only participants who reported being African-American/Black, Latino/Hispanic or White/Caucasian, male, HIV positive, and behaviorally bisexual in the past 5 years were selected. Participants were offered $\$ 40$ to participate in a face-toface interview that lasted between 90 and $120 \mathrm{~min}$. Informed consent and interviews were administered by trained project staff in a private room at a large AIDS service organization.

Detailed sexual histories were collected for the respondent's most recent male and/or female primary partner and three most recent casual partners. Where the three casual partners were all of the same sex, additional information on a fourth casual partner of a different sex-if the respondent had such a partner-was requested. Participants were instructed to respond based on their sexual behavior since they learned that they were HIV positive or within the past 5 years, whichever was more recent. Primary partners were defined to participants as "a partner you would call your boyfriend, girlfriend, spouse, significant other, husband, wife, life partner, or primary sexual partner" and casual partners as "people you had sex with who are partners you dated casually, tricks, one-night stands, friends you have sex with, and any other non-primary sexual contacts." This produced a data set of $150 \mathrm{MSMW}$ who reported on their relationships with 597 partners. Data of 7 partners and 2 MSMW were dropped due to missing values on the dependent or independent variables. The analytical sample includes 148 MSMW who reported on 590 partners. 
Measures

Assessment instruments were used that have shown strong psychometric properties in prior research that included HIV positive MSMW [35]. Items were refined based on formative research with HIV positive MSMW. For instance, the instrument was amended to allow for up to two primary partners (one male and one female partner; or one transgender partner and one male or female partner) and up to four casual male and female partners.

\section{Disclosure of HIV Positive Status}

Participants were asked a series of questions regarding their disclosure to specific primary and casual partners. Qualitative studies of the process of disclosure of HIVstatus observe that while some HIV positive individuals explicitly self-disclose, others use a combination of indirect hints or clues (e.g., the visible placement of HAART medication in the bathroom), and verbal and nonverbal cues (e.g., discussions of specific HAART medications) to communicate seropositivity to partners [36]. This informed our use of questions that were worded to capture both direct and indirect disclosure.

Questions about disclosure to primary partners versus casual partners differed slightly in their phrasing. Regarding their primary male and female partners, respondents were asked, (1) "Did (partner \#) know that you were HIV positive at any time before the first time you had sex?" If no, they were asked, (2) "Does (partner \#) know that you are HIV positive now?" Disclosure of HIV status was coded as nondisclosure, disclosure before sex, and disclosure after sex. A negative response to both questions was coded as nondisclosure; an affirmative response to the first question was coded as disclosure before sex; and a negative response to the first question and an affirmative response to the second question was coded as disclosure after sex. For casual partners the following questions were asked: (1) "Does (partner \#) know that you are HIV positive?" and (2) "When did (partner \#) find out that you are HIV positive?" The following response categories were given: "S/he knew my HIV status before we met," "The first time we met," "Before we had sex," "Before we had unprotected sex," "After we had unprotected sex." The first four categories were collapsed to represent disclosure before sex provided the respondent reported that the partner knew the respondent was HIV positive. If respondents reported that the partner did not know the respondent's HIV status, this was coded as nondisclosure. A positive response to the first question and the response "After we had unprotected sex" to the second question was coded as disclosure after sex.
Respondent Characteristics

A range of demographic information was collected for each respondent, including age and race/ethnicity, and HIV health status.

\section{Sexual Orientation}

Sexual orientation was assessed using a standard self-identification item: "Do you identify yourself as: (1) Straight/ Heterosexual, (2) Bisexual, or (3) Gay/Homosexual”.

\section{Responsibility to Disclose HIV Positive Status}

Feelings of responsibility for disclosing HIV status to partners was measured using the ratings of five items on a 5-point scale from strongly disagree (1) to strongly agree (5): "I have a responsibility to let people I'm going to have sex with know that I am HIV positive," "I shouldn't have to disclose my HIV status if I only have safe sex (reverse coded)," "If a potential partner doesn't ask about my HIV status, it's not my responsibility to tell him or her (reverse coded)," and "When I meet a new sex partner, they don't expect me to tell them my HIV status right away." Reliability for the four-item scale was moderate $(\alpha=0.70)$.

\section{Undetectable Viral Load}

Participants were asked to self-report their most recent viral load as part of a series of health status items. This continuous viral load number was re-coded as a binary variable, $0=$ detectable and $1=$ undetectable, where undetectable was equivalent to $<48$ copies per $\mathrm{mL}$.

\section{Partner Characteristics}

MSMW were asked to report their partner's gender, race/ ethnicity, HIV status if they knew it, and relationship partner status (primary or casual). HIV status of primary partners was measured explicitly as that partner's status at the first time he or she and the respondent had sex, whereas HIV status of casual partners was more ambiguously measured simply as that partner's status. Thus, casual partner's status may capture current rather than prior HIV status depending on how the participant interpreted the question if prior and current status differed.

\section{Analyses}

Descriptive statistics were produced for all sociodemographic, disclosure, and partner variables. To accommodate the structure of the data we used a multinomial logistic 
regression with partnerships $(N=590)$ clustered by respondents $(N=148)$ using survey estimators in STATA [37]. The clustered analyses adjust parameter estimates for the dependence of observations across respondents. For example, MSMW who disclose to one partner may be more likely to disclose to other partners by virtue of experience. In contrast, MSMW who do not disclose to one partner may be more likely to maintain this pattern of nondisclosure despite other respondent and partner characteristics. Multiple models are presented below: a pooled model in which partner sex is included as a predictor and thus, the effect parameters of all other variables are not allowed to vary by partner sex; and a model fully interacted by partner sex, where all effect parameters are allowed to vary by partner sex. Both models evaluate the effects of the same predictor variables with the exception of partner sex. Tests comparing the pooled and fully interacted models as well as comparing the joint effects of parameters across both outcome categories were conducted using adjusted Wald tests.

To assess robustness, the results of the multinomial logistic regression were compared against a multi-level model using the GLLAMM procedure [38] with partnerships nested within respondent. However the same pattern of effects was observed with only slight differences in the magnitude of effects and decreases in the size of standard errors compared to the clustered model. For ease of presentation and interpretation only the results of the clustered model are reported here. All analyses were conducted using STATA 9.2 [39].

\section{Results}

\section{Respondent Characteristics}

Sample characteristics for respondents and their reported partners are presented in Table 1. Participants ranged in age from 20 to 59 years old ( $M=39.8$ years). Respondents largely identified as bisexual (58\%) or gay/homosexual $(37 \%)$, with the remainder identifying as straight/heterosexual (5\%). MSMW provided sexual histories for a total of 590 partners, 5.2 partners on average $(\mathrm{SD}=0.74)$. Ninetynine MSMW (67\%) reported having a primary partner (male, female, or both) in the last 5 years. Of those reporting a primary partner, $43 \%$ of MSMW reported having a male primary partner, $11 \%$ of MSMW reported having a female primary partner, and $46 \%$ of MSMW reported having both a male and female primary partner in the past 5 years. All but one respondent reported having a casual partner in the last 5 years. Respondents reported on 2.9 male partners $(\mathrm{SD}=$ 1.02) and 1.4 female partners on average ( $\mathrm{SD}=0.64$ ). Although respondents could report on their most recent
Table 1 Sample characteristics

\begin{tabular}{|c|c|c|}
\hline & $\%(M)$ & $N(\mathrm{SD})$ \\
\hline \multicolumn{3}{|l|}{ Respondent characteristics $(N=148)$} \\
\hline Age & $(39.8)$ & (7.5) \\
\hline \multicolumn{3}{|l|}{ Race/ethnicity } \\
\hline Black & 33.1 & 50 \\
\hline Latino & 33.8 & 49 \\
\hline White & 33.1 & 49 \\
\hline \multicolumn{3}{|l|}{ Sexual orientation } \\
\hline Gay/homosexual & 36.5 & 54 \\
\hline Bisexual & 58.1 & 86 \\
\hline Straight/heterosexual & 5.4 & 8 \\
\hline Responsibility to disclose & $(3.5)$ & $(0.9)$ \\
\hline Undetectable viral load & 29.1 & 43 \\
\hline Number of partners in last 3 months & $(6.3)$ & $(15.8)$ \\
\hline Number of partners data collected for & $(5.2)$ & $(0.7)$ \\
\hline Male & $(2.9)$ & $(1.0)$ \\
\hline Female & $(1.4)$ & $(0.6)$ \\
\hline \multicolumn{3}{|l|}{ Partner characteristics $(N=590)$} \\
\hline \multicolumn{3}{|l|}{ Sex } \\
\hline Male & 69.3 & 409 \\
\hline Female & 30.7 & 181 \\
\hline \multicolumn{3}{|l|}{ Relationship type } \\
\hline Primary & 22.7 & 134 \\
\hline Casual & 77.3 & 456 \\
\hline \multicolumn{3}{|l|}{ HIV status } \\
\hline Positive & 29.3 & 173 \\
\hline Negative & 33.6 & 198 \\
\hline Unknown/untested & 37.1 & 219 \\
\hline
\end{tabular}

partners within a time period of up to 5 years, the median interval since last sex between the respondent and a given partner was 56 days $(M=218$ days, $\mathrm{SD}=365$ days); $90 \%$ reported having last had sex with a given partner within the previous 2 years.

Of those reporting at least one casual partner, 97\% reported at least one male casual partner and $79 \%$ reported at least one female casual partner. Differences in the distribution of male and female partners by respondent's selfidentified sexual orientation were significant $\left[\chi^{2}(2)=\right.$ 12.87; $p \leq 0.01]$, with straight/heterosexual identified MSMW reporting a higher proportion of female partners (57\%) compared to bisexually identified MSMW (34\%) and gay identified MSMW (24\%). There were no significant differences in the distribution of male and female partners across race/ethnicity.

\section{Partner Characteristics}

The lower panel of Table 1 presents the characteristics of all partners reported by respondents. Of the 590 partners, 
Table 2 Patterns of disclosure of HIV positive status to sexual partners by respondent characteristics and partner characteristics

\begin{tabular}{|c|c|c|c|c|c|c|c|}
\hline & \multicolumn{6}{|c|}{ Disclosure to sexual partners $(N=590)$} & \multirow[t]{3}{*}{$p$-value } \\
\hline & \multicolumn{2}{|c|}{ Before sex } & \multicolumn{2}{|c|}{ After sex } & \multicolumn{2}{|l|}{ Never } & \\
\hline & $\%(M)$ & $N(\mathrm{SD})$ & $\%(M) \mathrm{d}$ & $N(\mathrm{SD})$ & $\%(M)$ & $N(\mathrm{SD})$ & \\
\hline \multicolumn{8}{|l|}{ Respondent characteristics } \\
\hline Total & 56.1 & 331 & 10.5 & 62 & 33.4 & 197 & \\
\hline Race/ethnicity & & & & & & & 0.013 \\
\hline Black $^{\mathrm{a}, \mathrm{b}}$ & 55.4 & 112 & 10.9 & 22 & 33.7 & 68 & \\
\hline Latino $^{\mathrm{a}}$ & 48.9 & 92 & 9.0 & 17 & 42.0 & 79 & \\
\hline White ${ }^{\mathrm{b}}$ & 63.5 & 127 & 11.5 & 23 & 25.0 & 50 & \\
\hline Sexual orientation & & & & & & 0.411 & \\
\hline Gay/homosexual & 56.0 & 130 & 8.2 & 19 & 35.8 & 83 & \\
\hline Bisexual & 56.7 & 191 & 11.6 & 39 & 31.8 & 107 & \\
\hline Straight/heterosexual & 47.6 & 10 & 19.0 & 4 & 33.3 & 7 & \\
\hline Responsibility to disclose & $(3.8)^{\mathrm{a}}$ & $(0.5)$ & $(3.5)^{\mathrm{b}}$ & $(0.1)$ & $(3.1)^{\mathrm{c}}$ & $(0.1)$ & 0.000 \\
\hline Undetectable viral load & & & & & & & 0.972 \\
\hline Yes & 55.4 & 97 & 10.9 & 19 & 33.7 & 59 & \\
\hline No & 56.4 & 234 & 10.4 & 43 & 33.3 & 138 & \\
\hline \multicolumn{8}{|l|}{ Partner characteristics } \\
\hline Sex & & & & & & & 0.241 \\
\hline Male & 57.9 & 237 & 9.3 & 38 & 32.8 & 134 & \\
\hline Female & 51.9 & 94 & 13.3 & 24 & 34.8 & 63 & \\
\hline Relationship type & & & & & & & 0.000 \\
\hline Primary & 64.9 & 87 & 28.4 & 38 & 6.7 & 9 & \\
\hline Casual & 53.5 & 244 & 5.3 & 24 & 41.2 & 188 & \\
\hline HIV status & & & & & & & 0.000 \\
\hline HIV positive ${ }^{\mathrm{a}}$ & 91.3 & 158 & 6.4 & 11 & 2.3 & 4 & \\
\hline HIV negative ${ }^{b}$ & 63.6 & 126 & 19.7 & 39 & 16.7 & 33 & \\
\hline Unknown/untested $^{c}$ & 21.5 & 47 & 5.5 & 12 & 73.1 & 160 & \\
\hline
\end{tabular}

Categories or means that do not have superscript letters in common are significantly different from each other at the $p<0.05$ level

$181(31 \%)$ were female partners and $409(69 \%)$ were male partners. Primary partners constituted $23 \%$ of all partners reported; the remaining $77 \%$ of partners were casual partners. Roughly two-thirds of all partners were known by the MSMW to be HIV positive (29\%) or HIV negative $(34 \%)$. The remaining $37 \%$ of partners were of unknown status or had not been tested. Differences in the distribution of male and female partners across relationship type were marginally significant $\left[\chi^{2}(1)=3.59 ; p=0.058\right]$, with a greater proportion of female partners $(28 \%)$ being primary partners compared to male partners $(21 \%)$, while a greater proportion of male partners (79\%) were casual partners compared to female partners (72\%). Differences in the distribution of HIV status by partner sex were also significant $\left[\chi^{2}(2)=\right.$ $34.85 ; p \leq 0.001]$, with a greater proportion of male partners being HIV positive $(36 \%)$, a greater proportion of female partners being HIV negative (48\%), and equal proportions of each being unknown or untested (37\% male, $37 \%$ female).
Disclosure to Male and Female Partners

The distribution of disclosure to partners across respondent and partner characteristics are presented in Table 2. Overall, MSMW disclosed their HIV positive status before sex in $56 \%$ of partnerships. MSMW disclosed to an additional $11 \%$ of partners some time after having sex. In $33 \%$ of partnerships MSMW did not disclose their HIV status. Collapsing the disclosure before sex and after sex categories-a typical binary measure of disclosure-MSMW ever disclosed to $67 \%$ of all partners. In bivariate analyses, the timing of disclosure is similar for male and female partners $\left[\chi^{2}(2)=2.85 ; p=0.241\right]$, with roughly half of MSMW disclosing before sex (58\% male, $52 \%$ female) and roughly one-third never disclosing to male $(33 \%)$ or female partners $(35 \%)$.

Table 3 presents the unadjusted and adjusted odds ratios of disclosure before and after sex compared to never from a series of clustered multinomial logistic models. In the first 
Table 3 Unadjusted and adjusted odds ratios of disclosure from a series of clustered multinomal logistic models

\begin{tabular}{|c|c|c|c|c|c|c|c|c|}
\hline & \multirow{2}{*}{\multicolumn{2}{|c|}{ Unadjusted }} & \multicolumn{6}{|c|}{ Adjusted } \\
\hline & & & \multicolumn{2}{|c|}{ Pooled } & \multicolumn{2}{|c|}{ Male partners only } & \multicolumn{2}{|c|}{ Female partners only } \\
\hline & OR & $95 \% \mathrm{CI}$ & OR & $95 \% \mathrm{CI}$ & OR & $95 \% \mathrm{CI}$ & OR & $95 \% \mathrm{CI}$ \\
\hline \multicolumn{9}{|l|}{ Disclosure before sex } \\
\hline Female partner & 0.84 & $0.58-1.23$ & 0.93 & $0.55-1.57$ & - & & - & \\
\hline \multicolumn{9}{|l|}{ Respondent characteristics } \\
\hline \multicolumn{9}{|l|}{ Race/ethnicity } \\
\hline White (reference) & 1.00 & & 1.00 & & 1.00 & & 1.00 & \\
\hline Black & 0.65 & $0.33-1.26$ & 0.82 & $0.34-1.57$ & 0.75 & $0.26-2.12$ & 0.95 & $0.29-3.08$ \\
\hline Latino & 0.46 & $0.25-0.84 *$ & 0.89 & $0.38-2.01$ & 0.80 & $0.29-2.19$ & 0.99 & $0.29-3.37$ \\
\hline \multicolumn{9}{|l|}{ Sexual orientation } \\
\hline Bisexual (reference) & 1.00 & & 1.00 & 1.00 & 1.00 & & 1.00 & \\
\hline Gay/homosexual & 0.88 & $0.52-1.48$ & 0.75 & $0.37-1.51$ & 0.57 & $0.26-1.29$ & 1.20 & $0.44-3.33$ \\
\hline Straight/heterosexual & 0.80 & $0.23-2.83$ & 0.73 & $0.15-0.60$ & 0.74 & $0.10-5.36$ & 0.76 & $0.14-4.31$ \\
\hline Responsibility to disclose & 2.30 & $1.72-3.09 * * *$ & 2.69 & $1.80-4.03 * * *$ & 2.74 & $1.74-4.30 * * *$ & 2.80 & $1.56-5.00 * * *$ \\
\hline Undetectable viral load & 0.97 & $0.54-1.75$ & 1.00 & $0.45-2.20$ & 1.06 & $0.47-2.41$ & 0.98 & $0.31-3.13$ \\
\hline \multicolumn{9}{|l|}{ Partner characteristics } \\
\hline Casual partner & 0.13 & $0.06-0.28 * * *$ & 0.23 & $0.10-0.52 * * *$ & 0.25 & $0.08-0.73 * *$ & 0.19 & $0.07-0.57 * *$ \\
\hline \multicolumn{9}{|l|}{ Partner HIV status } \\
\hline HIV positive (reference) & 1.00 & & 1.00 & & 1.00 & & 1.00 & \\
\hline HIV negative & 0.10 & $0.03-0.27 * * *$ & 0.08 & $0.03-0.25 * * *$ & 0.11 & $0.03-0.35 * * *$ & $0.00^{\mathrm{a}}$ & $0.00-0.00 * * *$ \\
\hline Unknown/untested & 0.01 & $0.00-0.02 * * *$ & 0.01 & $0.00-0.02 * * *$ & 0.01 & $0.00-0.03 * * *$ & $0.00^{\mathrm{a}}$ & $0.00-0.00^{* * *}$ \\
\hline$N$ respondents & 148 & & 148 & & 145 & & 134 & \\
\hline$N$ partners & 590 & & 590 & & 409 & & 181 & \\
\hline \multicolumn{9}{|l|}{ Disclosure after sex } \\
\hline Female partner & 1.34 & $0.80-2.25$ & 0.79 & $0.38-1.65$ & - & & - & \\
\hline \multicolumn{9}{|l|}{ Respondent characteristics } \\
\hline \multicolumn{9}{|l|}{ Race/ethnicity } \\
\hline White (reference) & 1.00 & & 1.00 & & 1.00 & & 1.00 & \\
\hline Black & 0.70 & $0.31-1.61$ & 0.75 & $0.26-2.23$ & 0.70 & $0.22-2.22$ & 0.83 & $0.19-3.66$ \\
\hline Latino & 0.47 & $0.22-0.99 *$ & 0.61 & $0.23-1.56$ & 0.45 & $0.14-1.45$ & 1.08 & $0.21-5.58$ \\
\hline \multicolumn{9}{|l|}{ Sexual orientation } \\
\hline Bisexual (reference) & 1.00 & & 1.00 & & 1.00 & & 1.00 & \\
\hline Gay/homosexual & 0.63 & $0.32-1.24$ & 0.60 & $0.25-1.41$ & 0.41 & $0.15-0.94 *$ & 1.45 & $0.32-6.49$ \\
\hline Straight/heterosexual & 1.57 & $0.52-4.68$ & 2.62 & $0.61-11.22$ & 2.25 & $0.19-9.15$ & 3.39 & $0.65-9.86$ \\
\hline Responsibility to disclose & 1.45 & $0.95-2.23^{\dagger}$ & 1.54 & $0.95-2.52^{\dagger}$ & 1.41 & $0.80-2.48$ & 2.05 & $1.05-4.01 *$ \\
\hline Undetectable viral load & 1.03 & $0.50-2.14$ & 1.09 & $0.41-2.93$ & 1.02 & $0.34-3.05$ & 1.31 & $0.28-6.14$ \\
\hline \multicolumn{9}{|l|}{ Partner characteristics } \\
\hline Casual partner & 0.03 & $0.01-0.07 * * *$ & 0.05 & $0.02-0.12 * * *$ & 0.05 & $0.02-0.17 * * *$ & 0.04 & $0.01-0.14 * * *$ \\
\hline \multicolumn{9}{|l|}{ Partner HIV status } \\
\hline HIV positive (reference) & 1.00 & & 1.00 & & 1.00 & & 1.00 & \\
\hline HIV negative & 0.43 & $0.13-1.48$ & 0.42 & $0.10-1.73$ & 0.59 & $0.13-2.67$ & $0.00^{\mathrm{a}}$ & $0.00-0.00 * * *$ \\
\hline Unknown/untested & 0.03 & $0.01-0.10^{* * *}$ & 0.04 & $0.01-0.19 * * *$ & 0.05 & $0.01-0.25 * * *$ & $0.00^{\mathrm{a}}$ & $0.00-0.00 * * *$ \\
\hline$N$ respondents & 148 & & 148 & & 145 & & 134 & \\
\hline$N$ partners & 590 & & 590 & & 409 & & 181 & \\
\hline
\end{tabular}

${ }^{\dagger} p<0.10 ; * p<0.05 ; * * p<0.01 ; * * * p<0.001$

a Despite approaching zero, the odds ratio for disclosure before sex to HIV negative female partners compared to HIV positive partners does not reflect an absence of cases for female partners 
panel of Table 3, the unadjusted odds of disclosure before sex to female partners relative to male partners are less than one but nonsignificant: $\mathrm{OR}=0.84$ (95\% CI: 0.58 , 1.23). Evidence for less frequent disclosure to female partners before sex remains limited in the adjusted pooled model as the gap between male and female partners in the odds of disclosure before sex decreases from 0.16 to 0.07 when other known determinants of disclosure are controlled for. Further, a Wald test (adjusted for the dependency of observations) of the joint effect of being a female partner rather than a male partner across disclosure outcomes is nonsignificant $[F(2,146)=3.72 ; p=0.16]$. The odds of disclosure to female partners remain equal to the odds of disclosure to male partners in the pooled model after differences in rates of disclosure by other respondent and partner characteristics are controlled for $(\mathrm{OR}=0.93$ : 95\% CI: $0.55,1.57)$.

Two additional models are shown in the right-most panels of Table 3 which are equivalent to a model that is fully interacted by partner sex and allows the effects of all variables to vary for male and female partners. Notably, the parameters estimated for male partners are significantly different from those estimated for female partners $[F(18,130)=17.21 ; p<0.000]$.

\section{Additional Factors Influencing Disclosure}

The independent effects of all respondent characteristics on disclosure were also estimated. The odds that Black and Latino MSMW disclose before sex are 35\% (OR $=0.65$; 95\% CI: $0.33,1.26)$ and $54 \%$ less $(\mathrm{OR}=0.46 ; 95 \% \mathrm{CI}$ : $0.25,0.84)$, respectively, than the odds White MSMW disclose before sex in the unadjusted model; however, only the unadjusted odds ratio for Latino MSMW is significantly different from one $(p \leq 0.05)$. In the successive multivariate models, the effect of race/ethnicity on disclosure behavior loses significance: the odds of disclosure before and after sex are similar for Blacks $(\mathrm{OR}=0.82 ; 95 \% \mathrm{CI}$ : $0.34,1.57)$, Latinos (OR $=0.83$; 95\% CI: 0.38, 2.01), and Whites (reference), and a Wald test of the joint effect of race/ethnicity across disclosure outcomes confirms that differences in disclosure by race/ethnicity are nonsignificant in the pooled model $[F(4,144)=0.34 ; p=0.85]$.

We next consider differences in disclosure by sexual orientation. Neither the unadjusted nor the adjusted effects of self-identified sexual orientation are significantly different from one for disclosure before sex. However, the odds that gay-identified MSMW disclose after sex are 59\% less than the odds that bisexually-identified MSMW disclose after sex in the male partner only model $(\mathrm{OR}=0.41$; 95\% CI: 0.15, 0.94)].

The remaining respondent characteristics included in the model are feelings of responsibility before sex and respondent's self-reported viral load. In the pooled model feelings of responsibility to disclose are positively associated with disclosure: net of other individual and partner characteristics each unit increase in feelings of responsibility to disclose increases the odds of disclosure before sex compared to never by a factor of 2.7 (95\% CI: 1.80, 4.03). The effect of greater feelings of responsibility on disclosure before sex is consistent for male and female partners: a one unit increase in responsibility score increases the adjusted odds of disclosure after sex by roughly three times for both male $(\mathrm{OR}=2.74 ; 95 \% \mathrm{CI}: 1.74,4.30)$ and female partners $(\mathrm{OR}=2.80 ; 95 \% \mathrm{CI}: 1.56,5.00)$.

The effect of reporting an undetectable viral load on disclosure behavior is nonsignificant in all bivariate and multivariate models, a finding which may be attributable to the small number of men who reported their viral load as undetectable $(N=59)$.

Consistent with literature on disclosure among MSM, the odds of disclosure before sex and after sex are greatly affected by relationship partner type and partner's HIV status. Overall, MSMW are substantially less likely to disclose to casual partners compared to primary partners and to HIV negative and unknown partners compared to HIV positive partners. In the pooled model, the odds of disclosure before sex to casual partners are $77 \%$ less than the odds of disclosure before sex to primary partners $(\mathrm{OR}=0.23 ; 95 \% \mathrm{CI}: 0.10,0.52)$. The odds that MSMW disclose to casual partners after sex are, not surprisingly, even smaller: the odds of disclosure after sex to casual partners are $95 \%$ less than the odds of disclosure after sex to primary partners $(\mathrm{OR}=0.05 ; 95 \% \mathrm{CI}: 0.02,0.12)$. The effect of being a casual partner is similar across the unpooled male and female models which estimate effects separately for male and female partners. However, the effect of partner's HIV status varied significantly for male and female partners. Although the odds of disclosure to known HIV negative male partners are $89 \%$ less than the odds for HIV positive male partners $(\mathrm{OR}=0.11$; $95 \% \mathrm{CI}$ : $0.03,035)$, the odds of disclosure before sex to HIV negative female partners compared to HIV positive female partners $(\mathrm{OR}=0.00 ; 95 \% \mathrm{CI}: 0.00,0.00)$ are substantially lower and significantly less than the odds of disclosure before sex for HIV negative male partners compared to HIV positive male partners $[F(2,146)=62.33 ; p<0.000]$. The gap in disclosure to HIV negative male and female partners widens after sex.

Figure 1 depicts the predicted probabilities of disclosure before sex, after sex, and never to male and female primary and casual partners by partner HIV status. Predicted probabilities were estimated using parameters from the fully interacted model. In this figure, the preference to disclose before sex to primary and known HIV positive partners, regardless of partner sex, is apparent. Further, 
Fig. 1 Predicted probability of disclosure of HIV status by partner sex, relationship status, and partner HIV status

\section{Disclosure before Sex}
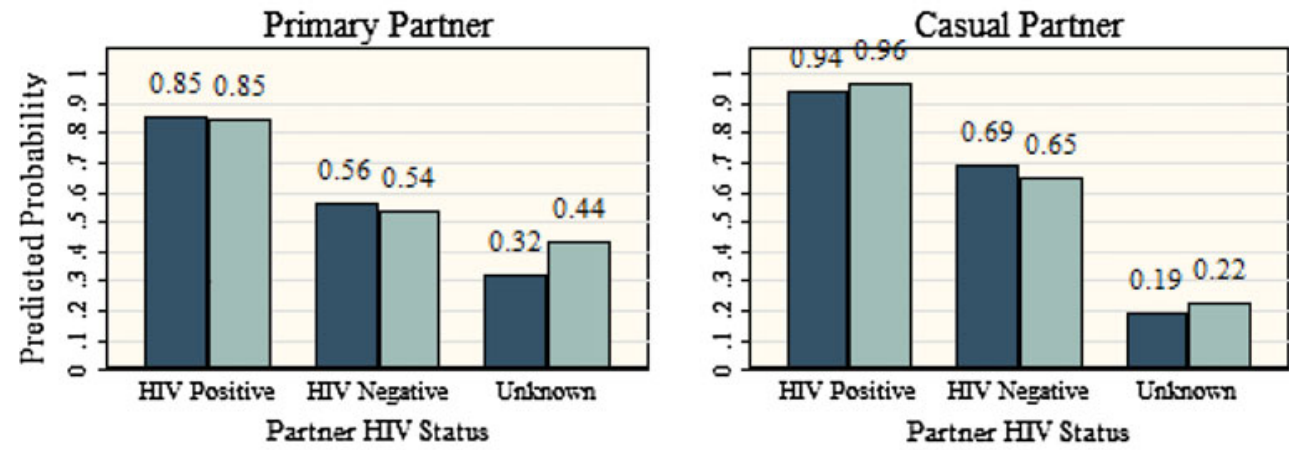

Disclosure after Sex
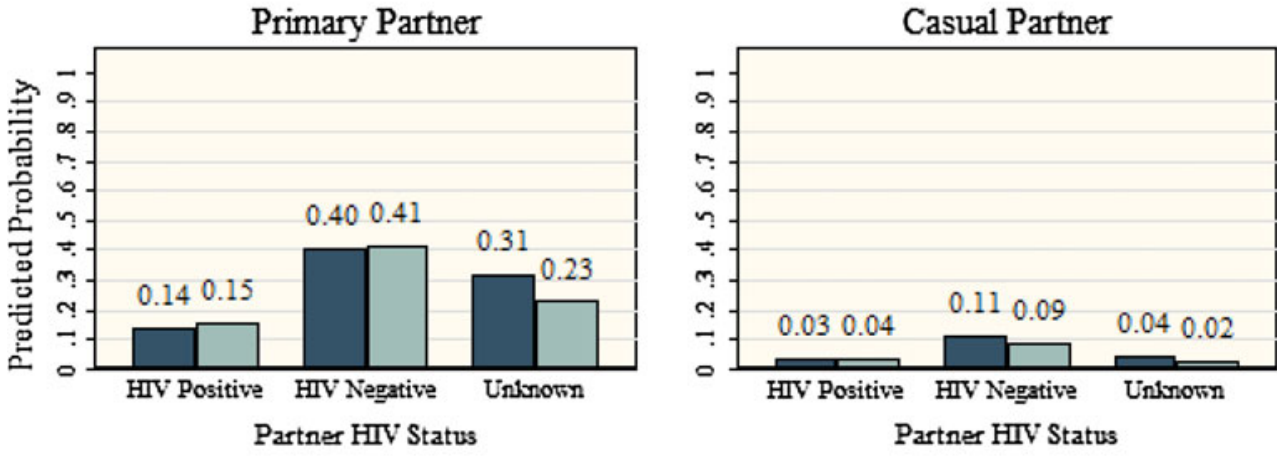

Nondisclosure
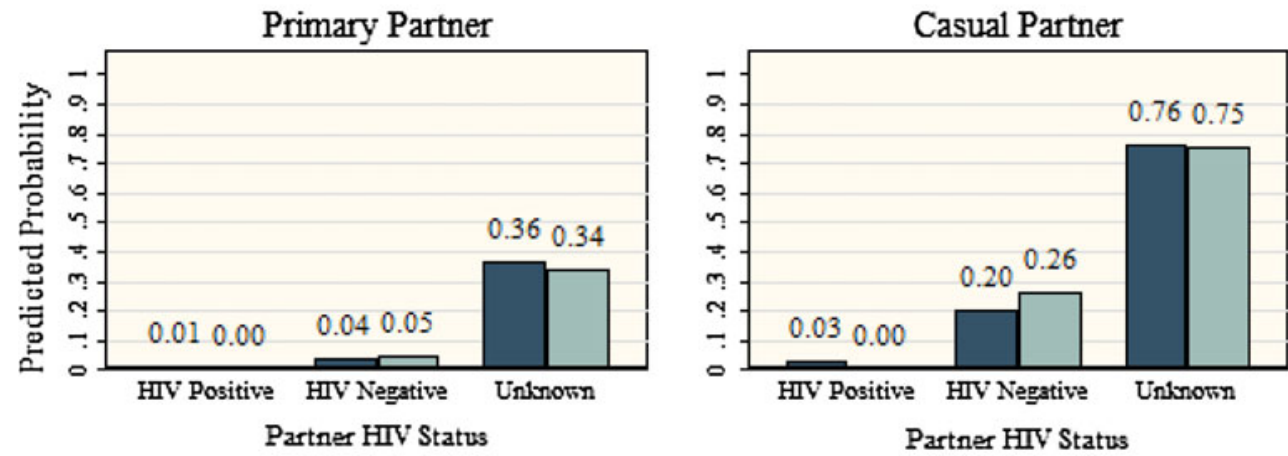

Male
Figure 1 depicts patterns of mutual nondisclosure and nonreciprocal disclosure (discussed in more detail below) among both male and female HIV negative and unknown status partners.

\section{Discussion}

The first aim of this paper was to provide much needed data on the disclosure of HIV positive status to male and female partners of MSMW. Overall, MSMW disclosed their HIV status before sex to slightly more than half of all partners and never disclosed their HIV status to one-third of partners. This finding that $33 \%$ of all partners were unaware of the respondents HIV positive status is well within the range of nondisclosure observed by O'Brien and colleagues (2-52\%) in studies conducted between 1991 and 2001 with MSM [9].

These data do not support the conclusion that MSMW systematically disclose their HIV status less to female partners compared to male partners; in bivariate and multivariate analyses there were no significant differences in 
the odds of disclosure to male and female partners. However, decisions of whether and when to disclose do reflect broader social and relationship contexts that impact male and female partners differently. It has long been recognized that HIV positive MSM are more likely to disclose their HIV status to primary partners than to casual partners. Notably, this finding is replicated among MSMW for both male and female primary partners providing many linkages with previous qualitative and quantitative work that has shown a strong preference for disclosure to primary partners $[8,10,11]$. Knowledge of partner's HIV status also remains a strong predictor of disclosure among MSMW. In this study, HIV negative and unknown status partners regardless of sex were at a substantial disadvantage compared to HIV positive partners. However, the effect of partner's HIV status varies significantly in magnitude for male and female partners. Although neither male nor female HIV negative partners had very high odds of disclosure before sex compared to their HIV positive counterparts, HIV negative male partners had higher odds of being disclosed to before sex than HIV negative female partners.

These findings should prompt additional work that further considers the process and meaning of disclosure to male and female sexual partners among MSMW. While rates of disclosure were similar overall, the processes and motivations that result in roughly one half of male and female partners having no information about MSMW's HIV status may be different. In the present study feelings of responsibility emerged as a significant predictor of disclosure to both male and female partners while undetectable viral load was not related to disclosure behavior or feelings of responsibility to disclose. Given mixed findings in previous research on health status indicators like viral load [40, 41], as well as noted discrepancies between selfreport and biomarker data [40], it was unclear what relationship undetectable viral load would have with disclosure before sex and to feelings of responsibility to disclose (data not shown), but no association with either was found among male and female partners.

Work examining the nuances and sources of feelings of responsibility as they related to male versus female partners would considerably improve our understanding of disclosure behavior. Several qualitative studies offer some insight here. In their study of HIV status disclosure among MSM, Gorbach and colleagues suggest that a communitywide "Don't ask, Don't tell" norm, or mutual nondisclosure, regulates discussions of HIV status among MSM and their male casual partners. Sheon and Crosby have argued that the adoption of such a norm has been driven by the shift in HIV prevention towards individually-oriented rather than community-oriented risk reduction and responsibility for prevention [42]. As a result of this shift,
HIV positive MSM are suggested to share an expectation of individual responsibility for one's own risk behaviors and thus, may be able to avoid disclosing their HIV status to casual male partners.

In the present study, we find evidence of a "Don't ask, Don't tell" norm among casual partners, and to a lesser extent among primary partners, regardless of partner sex. In Fig. 1, the predicted probabilities of no information exchange (i.e., nondisclosure to unknown status partners) between MSMW and their male and female casual partners are 76 and $75 \%$, respectively. Among male and female primary partners, this probability decreases but remains well above zero at 36 and $34 \%$, respectively. In addition to "Don't ask, Don't tell," however, we also find evidence of a slightly different phenomenon: nonreciprocal disclosure. In their qualitative interviews, Gorbach and colleagues found that a few MSM did not disclose their HIV positive status to partners who had told respondents that they were HIV negative. Similarly, we find that the predicted probabilities of nondisclosure to male and female casual partners that respondents know to be HIV negative are 20 and $26 \%$, respectively. These figures are well above those estimated for disclosure to HIV negative primary partners (4\% male, 5\% female) and HIV positive partners, primary ( $1 \%$ male, $0 \%$ female) or casual (3\% male, $0 \%$ female). Although we see similar patterns of mutual nondisclosure and nonreciprocal disclosure among male and female partners in our data, the various ways that partner sex may inform the decisions of MSMW to disclose their HIV positive status to sexual partners, particularly those who are HIV negative and unknown status, remain understudied.

Despite community norms, several studies remind us that individual factors not addressed by the present study remain important for understanding disclosure behaviors. HIV positive individuals who consistently disclose (or consistently do not disclose) may have more fully incorporated (or negated) an HIV positive identity with the self [43] compared to individuals who disclose to some partners but not others. The substantial proportion of HIV positive MSM found by Parsons and colleagues to not consistently engage in disclosure or nondisclosure [32] may be involved in the process of maturing as a discloser [8] or may be guided by "disclosure policies" they have formed to respond to social and situational factors [44, 45]. Despite the inconsistent association of disclosure before sex with sexual risk behavior [21, 46-48], understanding the individual and social contributions to disclosure behavior continue to be important for HIV prevention research as findings from studies of sexual risk behaviors among HIV positive MSM in the United States show that, while most HIV-positive partners attempt to protect sexual partners, a substantial minority (26\%) continue to report unprotected anal intercourse with unknown or HIV-negative partners 
[41] — a finding in line with our discussion of mutual nondisclosure and nonreciprocal disclosure among MSMW above. In the present study, 140 MSMW (95\%) reported having at least one HIV negative or unknown status casual partner in the last 5 years. Of these, 70 (50\%) reported having any unprotected intercourse with an HIV negative or unknown status casual partner: $29 \%$ reported unprotected insertive anal intercourse with at least one of these partners (male or female), 34\% reported unprotected receptive anal intercourse, and $34 \%$ reported unprotected insertive vaginal intercourse.

A secondary aim of this paper was to provide an improvement on previous studies of disclosure by addressing two technical issues related to the study of disclosure. First, although disclosure is often measured as a binary variable, in the present study disclosure was measured at three levels: disclosure before sex, disclosure after sex, and nondisclosure. This distinction is in line with calls from Niccolai and colleagues [29] as it separates disclosures that could preemptively have had an effect on sexual risk from disclosures that happened eventually, perhaps even after sexual activity between the two partners had ended. As a result of this distinction, we see that other studies of disclosure may have overestimated disclosure substantially: although MSMW disclosed their HIV positive status to $67 \%$ of partners overall (binary), MSMW only disclosed to $56 \%$ of partners before sex.

Second, disclosure patterns were evaluated at the partnership level across multiple partnerships in contrast to the majority of studies that estimate disclosure patterns based on the most recent sexual partner. Collecting data on the most recent partner was explicitly adopted by Marks and Crepaz as a strategy to decrease recall bias in sexual history data over longer time periods. In the conclusion of their article on self-disclosure, Marks and Crepaz discuss their assumptions that disclosure and its relation to safer sex practices is likely similar across partners but ultimately leave it to future studies to confirm the representativeness of disclosure to an individual's most recent partner. Given the observed variability in parameter estimates, as well as Niccolai and colleagues' assessment that a substantial portion $(28 \%)$ of the variance in disclosure behavior occurs within individuals; the present study rejects this assumption and utilizes sexual history data for up to one male and one female primary partner and up to four of the respondent's casual partners in the 5 years prior to interview. This data structure retains several advantages over a singular observation of the most recent partner: it allows for more exact estimates of the effects of respondent and partner characteristics through the use of models that account for within-individual variation in disclosure behaviors across partners not due to controlled covariates, and it maximizes observations for female partners. Further, although respondents could report on their most recent partners within a time period of up to 5 years, less than $10 \%$ of respondents reported on sexual partnerships that ended more than 2 years prior to interview.

Remarkably little work has considered the validity of self-reported disclosure of HIV status to partners with whom the respondent may have engaged in risk behaviors. Depending on the measure of disclosure and method of data collection, data may suffer from recall bias, social desirability bias, or both. Social desirability biases may prompt some MSMW to over report disclosure before sex generally to all partners or among a particular group of partners. Little work, including the present study, has incorporated measures of disclosure that aim to confirm respondent's reports of disclosure to a given target (e.g., via partner corroboration [49]) or social desirability scales to evaluate and correct for these biases. Though these data were collected in a face-to-face interview, a concerted effort was made to minimize the impact of social desirability biases in the reporting of disclosure behaviors: the study was conducted anonymously in small private offices in a large, unmarked office building, and interviewers were extensively trained to be attentive and supportive but also sensitive to any inconsistencies in participants' narratives that may cause concern for data quality.

These findings are particularly relevant for HIV-positive MSMW who are receiving HIV/AIDS related medical care or social services; results presented here may not be applicable to MSMW who are not seeking care, as care seeking indicates a certain level of acknowledgment of one's HIV status and increases the likelihood of encountering medical staff, other HIV positive individuals, and social support groups that may encourage open disclosure to sexual partners. Thus, the focus on a care-seeking population may overestimate disclosure generally as well as the similarity in disclosure behaviors across partner sex.

Nonetheless, the present study provides a detailed description of HIV disclosure patterns among MSMW across various respondent and partner characteristics. These patterns largely reflect patterns found in other populations of MSM, specifically with regard to relationship partner type and partner's HIV status, but overall do not show evidence for systematic differences in disclosure of HIV positive status by partner sex among MSMW. Further, we do not find that Black and Latino MSMW are significantly less likely to disclose their HIV status to partners when other respondent and partner characteristics are controlled for. Ultimately, this study highlights more the similarities rather than the differences in disclosure to male and female sexual partners among MSMW. However, it also points to a clear need to better understand the ways that MSMW think about and differentially navigate (non)disclosure of their HIV status to male and female 
partners, particularly to HIV negative or unknown status partners and to casual partners.

Acknowledgments An earlier version of this work was presented at the annual meeting of the American Public Health Association on October 27, 2008. The authors would like to thank the study participants; Leonardo Colemon, Miguel Chion, and Mark Schuster for their work on the study; Megan Sweeney for her instruction on analyses and comments on earlier drafts; and Stefan Timmermans for his advising on this project. Data collection was supported by the Universitywide AIDS Research Program (02-APLA-038). The first author was also supported by a fellowship grant funded by the State of California under the California HIV/AIDS Research Program and administered through the California Center for Collaborative HIV Research-Network for AIDS Research in Los Angeles (CH05-LA608).

Open Access This article is distributed under the terms of the Creative Commons Attribution Noncommercial License which permits any noncommercial use, distribution, and reproduction in any medium, provided the original author(s) and source are credited.

\section{References}

1. Chu S, Peterman T, Doll L, Buehler J, Curran J. AIDS in bisexual men in the United States: epidemiology and transmission ot women. Am J Pub Health. 1992;82:220-4.

2. Millett G, Malebranche D, Mason B, Spikes P. Focusing "down low": bisexual black men, HIV risk and heterosexual transmission. J Natl Med Assoc. 2005;97(7):52s-9s.

3. Montgomery J, Mokotoff E, Gentry A, Blair J. The extent of bisexual behavior in HIV-infected men and implications for transmission to their female sex partners. AIDS Care. 2003;15: 829-37.

4. McKirnan D, Stokes J, Doll L, Burzette R. Bisexually active men: social characteristics and sexual behavior. J Sex Res. 1995; 32(1):65-76.

5. Omarzu J. A disclosure decision model: determining how and when individuals will self-disclose. Pers Soc Psychol Rev. 2000; 4(2):174-85.

6. Mutchler MG, Bogart LM, Elliot MN, McKay T, Schuster MA. Psychosocial correlates of unprotected sex without disclosure of HIV-positivity among African-American and Latino men who have sex with men and women. Arch Sex Behav. 2008;37(5): 736-47.

7. Kalichman S, DiMarco M, Austin J, Luke W, DiFonzo K. Stress, social support, and HIV status disclosure to family and friends among HIV positive men and women. J Behav Med. 2003; 26(4):315-32.

8. Cusick L, Rhodes T. The Process of Disclosing Positive HIV Status: Findings from Qualitative Research. Cult Health Sex. 1999;1(1):3-18.

9. Harawa NT, Williams JK, Ramamurthi HC, Bingham TA. Perceptions towards condom use, sexual activity, and HIV disclosure among HIV-positive African American men who have sex with men: implications for heterosexual transfer. J Urban Health. 2006;83(4):682-94.

10. Derlega V, Winstead B, Folk-Barron L. Reasons for and against disclosing HIV-seropositive test results to an intimate partner: a functional perspective. In: Sporbert S, editor. Balancing the Secrets of Private Disclosures. Mahwah, NJ: Erlbaum; 2000. p. 53-69.
11. Hays R, McKusick L, Pollack L, Hillard R, Hoff C, Coates T. Disclosing HIV seropositivity to significant others. AIDS. 1993;7(3):425-31.

12. Derlega V, Winstead B, Geene K, Serovich J, Elwood W. Reasons for HIV disclosure/nondisclosure in close relationships: testing a model of HIV-disclosure decision making. J Soc Clin Psychol. 2004;23(6):747-67.

13. Klitzman R, Bayer R. Mortal secrets: truth and lies in the age of AIDS. Baltimore: The Johns Hopkins University Press; 2003.

14. Gorbach P, Galea J, Amani B, Shin A, Celum C, Kerndt P, et al. Don't ask, don't tell: patterns of HIV disclosure among HIV positive men who have sex with men with recent STI practising high risk behaviour in Los Angeles and Seattle. Sex Transm Infect. 2004;80(6):512-7.

15. Simoni J, Pantalone D. Secrets and safety in the age of AIDS: Does HIV disclosure lead to safer sex? Top HIV Med. 2004;12(4):109-18.

16. O'Brien M, Richardson-Altson G, Ayoub M, Mangus M, Peterman T, Kissinger P. Prevalence and correlates of HIV serostatus disclosure. Sex Transm Dis. 2003;30(9):731-5.

17. Duru O, Collins R, Ciccarone D, Morton S, Stall R, Beckman R, et al. Correlates of sex without serostatus disclosure among a national probability sample of HIV patients. AIDS Behav. 2006;10:495-507.

18. Niccolai L, Dorst D, Meyers L, Kissinger P. Disclosure of HIV status to sexual partners: predictors and temporal patterns. Sex Transm Dis. 1999;26(5):281-5.

19. Stein M, Freedberg K, Sullivan L, Savetsky J, Levenson S, Hingson R, et al. Sexual ethics: disclosure of HIV-positive status to partners. Arch Intern Med. 1998;158:253-7.

20. Wolitski R, Rietmeijer C, Goldbaum G, Wilson R. HIV serostatus disclosure among gay and bisexual men in four American cities: general patterns and relation to sexual practices. AIDS Care. 1998;10:599-610.

21. Klitzman R, Exner T, Correale J, Kirshenbaum S, Remien R, Ehrhardt A, et al. It's not just what you say: relationships of HIV disclosure and risk reduction among MSM in the post-HAART era. AIDS Care. 2007;19(6):749-56.

22. Ciccarone D, Kanouse D, Collins R, Miu A, Chen J, Morton S, et al. Sex without disclsure of positive HIV serostats in a US probility sample of persons receiving medical care for HIV infection. Am J Pub Health. 2003;93(6):949-54.

23. Klien F, Sepekoff B, Wolf T. Sexual orientation: a multi-variable dynamic process. In: Geller T, editor. Bisexuality: a reader and a sourcebook. Ojai, CA: Times Change Press; 1990. p. 64-81.

24. Diaz R. Latino gay men and HIV: culture, sexuality, and risk behavior. New York: Routledge; 1998.

25. Mason H, Marks G, Simoni J, Ruiz M, Richardson J. Culturally sanctioned secrets? Latino men's nondisclosure of HIV infection to family, friends, and lovers. Health Psychol. 1995;14(1):6-12.

26. Mays V, Cochran S, Zamudio A. HIV prevention research: are we meeting the needs of African American men who have sex with men? J Black Psychol. 2004;30:78-105.

27. Stokes J, Vanable P, McKirnan D. Ethnic differences in sexual behavior, condom use, and psychological variables among Black and White men who have sex with men. J Sex Res. 1996;29:1-14.

28. Mason H, Simoni J, Marks G, Johnson C, Richardson J. Missed opportunities? Disclosure of HIV infection and support seeking among HIV+ African American and European-American men. AIDS Behav. 1997;1(3):155-62.

29. Niccolai L, King E, D’Entremont D, Pritchett E. Disclosure of HIV serostatus to sex partners: a new approach to measurement. Sex Transm Dis. 2006;33(2):102-5.

30. Zea MC, Reisen CA, Poppen PJ, Echeverry JJ, Bianchi FT, Disclosure of HIV-positive status to Latino gay men's social networks. Am J Community Psychol. 2004;33(1/2):107-16. 
31. Crepaz N, Marks G. Serostatus disclosure, sexual communication and safer sex in HIV-positive men. AIDS Care. 2003;15(3): 379-87.

32. Parsons JT, Scrimshaw EW, Bimbi DS, Wolitski RJ, Gomez CA, Halkitis PN. Consistent, inconsistent, and non-disclosure to casual sexual partners among HIV-seropositive gay and bisexual men. AIDS. 2005;19:S87-97.

33. Diaz T, Chu S, Frederick M, Hermann P, Levy A, Mokotoff E. Sociodemographics and HIV risk behaviors of bisexual men with AIDS: results from a multistate interveiw project. AIDS. 1993; 7:1227-32.

34. Stokes J, Taywaditep K, Vanable P, McKirnan D. Bisexual men, sexual behavior and HIV/AIDS. In: Firestein B, editor. Bisexuality: the psychology and politics of an invisible minority. Thousand Oaks, CA: Sage Publications; 1996. p. 149-68.

35. Stall R. An agenda for gay men's health: The Urban Men's Health Study. In: Center for HIV indentification, prevention, and treatment services, Los Angeles: University of California Los Angeles; 1999.

36. Adams B. Constructing the neoliberal sexual actor: responsibility and care of the self in the discourse of barebackers. Cult Health Sex. 2005;7(4):333-46.

37. Long SJ, Freese J. Regression models for categorical dependent variables using Stata. 2nd ed. College Station, TX: Stata Press; 2006.

38. Rabe-Hasketh S, Skrondal A. Multilevel and longitudinal modeling using Stata. 2nd ed. College Station, TX: STATA Press; 2008.

39. StataCorp. StataCorp Statistical Software: Release 9. 2005.
40. Crepaz N, Hart TA, Marks G. Highly active antiretroviral therapy and sexual risk behavior. J Am Med Assoc. 2004;292(2):224-36.

41. Crepaz N, Marks G, Liau A, Mullins MM, Aupont LW, Marshall $\mathrm{KJ}$, et al. Prevalence of unprotected anal intercourse among HIVdiagnosed MSM in the United States: a meta-analysis. AIDS. 2009;23:1617-29.

42. Sheon N, Crosby G. Ambivalent tales of HIV disclosure in San Francisco. Soc Sci Med. 2004;58:2105-18.

43. Mayfield AE, Rice E, Flannery D, Rotheram-Borus MJ. HIV disclosure among adults living with HIV. AIDS Care. 2008; 20(1):80-92.

44. Rutledge SE. Enacting personal HIV disclosure policies for sexual situations: HIV-positive gay men's experiences. Qual Health Res. 2007;17:1040-59.

45. Rutledge SE. Formation of personal disclosure policies among HIV-positive men who have sex with men. AIDS Patient Care STDS. 2009;23(7):531-43.

46. Crepaz N, Marks G. Towards an understanding of sexual risk behavior in people living with HIV: a review of social, psychological, and medical findings. AIDS. 2002;16:135-49.

47. Kalichman S, Nachimsom D. Self-efficacy and disclosure of HIVpositive status to sex partners. Health Psychol. 1999;18:281-7.

48. Marks G, Crepaz N. HIV-positive men's sexual practices in the context of self-disclosure of HIV status. J Acquir Immune Defic Syndr. 2001;27:79-85.

49. Anglewicz PA, Bignami-Van Assche S, Clark S, Mkandawire J. HIV risk among currently married couples in rural Malawi: what do spouses know about each other? AIDS Behav. 2010;14(1): 103-12. 